\title{
Proteolytic Remodeling of the Synaptic Cell Adhesion Molecules (CAMs) by Metzincins in Synaptic Plasticity
}

\author{
Malgorzata Bajor $\cdot$ Leszek Kaczmarek
}

Received: 6 September 2012/Revised: 19 September 2012/Accepted: 25 October 2012/Published online: 4 November 2012

(C) The Author(s) 2012. This article is published with open access at Springerlink.com

\begin{abstract}
Cell adhesion molecules participate in the formation, maturation, function and plasticity of synaptic connections. The growing body of evidence indicates that in the regulation of the synaptic plasticity, in which these molecules play pivotal role, also the proteolytic processes are involved. This review focuses on extracellular proteolysis of the cell adhesion molecules by specific subgroup of the matrix metalloproteinases, a disintegrin and metalloproteases and a disintegrin and metalloproteinase with thrombospondin motifs, jointly referred to as metzincins, in driving coordinated synaptic structural and functional modifications underlying synaptic plasticity in the adult brain.
\end{abstract}

Keywords Proteolysis - Synapse - Dendritic spines · MMP · SynCAM · Cadherin

$\begin{array}{ll}\text { Abbreviations } & \\ \text { PS1/ } \gamma \text {-secretase } & \text { Presenilin 1/gamma-secretase } \\ \text { NMDA } & \text { N-Methyl-D-aspartic acid } \\ \text { cLTP } & \text { Chemical long term potentiation } \\ \text { PKC } & \text { Protein kinase C } \\ \text { MAP kinase } & \text { Mitogen-activated protein kinase } \\ \text { PI 3-kinase } & \text { Phosphoinositide 3-kinase } \\ \text { PTZ } & \text { Pentylenetetrazol }\end{array}$

Special Issue: In Honor of Elisabeth Bock.

M. Bajor $(\varangle) \cdot$ L. Kaczmarek

Laboratory of Neurobiology, Nencki Institute, 3 Pasteur Street, 02-093 Warsaw, Poland

e-mail: m.bajor@nencki.gov.pl

\section{Introduction}

After the initial establishment of neuronal connections during development, synapses remain highly dynamic and undergo activity-dependent changes in their efficacy and morphology. Communication between neurons at the synapses is mediated primarily by neurotransmitter release and by the gating of the postsynaptic receptor ion channels, but burgeoning evidence indicates that signaling is also mediated by adhesion molecules that interact in a homo- or heterophilic fashion across the synaptic cleft. Thus, cell adhesion molecules (CAMs) at the synapse mediate synaptic plasticity, the ability to change synaptic function, thought to underlie learning and memory, as well as implicated in a number of neuropsychiatric conditions. It is, however, still poorly understood how synaptic CAMs contribute to synapse formation and/or structure, and whether and/or how smaller groups of CAMs serve as minimal, functionally cooperative adhesive units upon which the structure is based [1].

An increasing number of studies support the idea that structural changes at the synapses are closely associated with synaptic plasticity. A majority of these dynamic changes in the synaptic microenvironment are regulated by various families of proteases, including mainly metzincins [2] and serine proteases. Their function is to cleave the proteins available in the extracellular matrix (ECM) and even to release signaling molecules from ECM and CAMs, which may play an essential role for changes in synaptic configuration. Notably, ECM remodeling affects both structural and functional plasticity, such as long-term potentiation (LTP), long-term depression (LTD), homeostatic plasticity, and metaplasticity [3]. Importantly, the synaptic remodeling involves a complex sequential proteolytic activation and interaction of different molecules 
resulting in the control of various processes acting at the synapse, such as receptors trafficking, cytoskeleton remodeling, formation, growth and morphological changes of new and existing dendritic spines. Notably, it has repeatedly been shown that the same target molecule can be recognized and processed by various proteases and the released soluble ectodomains of CAMs may interact with different ligands, leading to the generation of distinct signals.

\section{Proteolysis of Cell Adhesion Molecules}

At the synapse, cell adhesion molecules operate in synergistic association in the control of adhesive function and signal transduction by forming dynamic network rather than acting as independent molecules. Similarly, the processes associated with remodeling of neuronal connections are achieved by the concerted actions of several different proteases that are secreted by neurons and glial cells [4, 5]. One of the most prominent features between CAMs and proteases actions is that they are reciprocal. Metzincins are apparently the major effectors in remodeling the structures of neuronal circuits which contribute to the fine tuning of diverse biological processes through limited proteolysis of specific targets. Recent data strongly imply their important role in the modulation of morphology of dendritic spines which lead to changes in signaling pathway and molecules trafficking in the brain. Table 1 contains summary information on cleavage of CAMs by metzincins and the role of their proteolytic processing in synaptic plasticity.

\section{Cadherins}

Among the principal representatives of the CAMs are cadherins. Members of the cadherin superfamily share general expression profiles and have distinct functions during the brain development and in the mature brain function. Their main role is to tie up the pre- and postsynaptic part of synapse by homophilic interactions. Inside the cells, cadherins are bound to the actin cytoskeleton via $\beta$-catenins and affect synaptogenesis, maintenance of cellcell contact and dendritic spine morphology [6]. It was shown that surface population of cadherin molecules is regulated by proteolytic cleavage in the extracellular matrix or intracellular milieu. Neuronal cadherin (N-cadherin) undergoes the ectodomain cleavage by at least two membrane-bound matrix metalloproteinases (MMPs), ADAM10 and membrane type 5-matrix metalloproteinase (MT5-MMP), followed by the intramembrane proteolysis mediated by PS1/ $\gamma$-secretase complex [7-10]. ADAM10 plays a crucial role in the complex sequence of events that regulates dendritic spine maturation and/or stabilization and in the modulation of the structural organization of the glutamatergic synapse [7]. The ADAM10 driven processing in response to calcium influx via NMDA type glutamate receptor is required for the subsequent PS $1 / \gamma$ secretase cleavage of $\mathrm{N}$-cadherin, which leads to releasing of a cytoplasmic fragment. This process is called regulated intramembrane proteolysis (RIP), in which removal of the ectodomain by shedding is necessary for the second cleavage catalyzed by $\gamma$-secretase [11]. The proteolytic processing of $\mathrm{N}$-cadherin affects the interaction between $\mathrm{N}$-cadherin and $\beta$-catenin, leading to release of $\beta$-catenin from the cell surface and directing it to the nucleus, to regulate genes involved in the proliferation of neuronal stem cells, neuronal differentiation, axonal remodeling and synaptogenesis [9]. It might be suggested that such proteolytic modulation of $\beta$-catenin interaction with $\mathrm{N}$-cadherin may be a substantial molecular mechanism for the synaptic plasticity.

Recently, Gardoni et al. [12] have shown that PACAP38 has an impact on the modulation of dendritic spine morphology through the ADAM10-N-cadherin-AMPA receptor signaling pathway. Pituitary adenylate cyclaseactivating polypeptide 38 (PACAP38) is neuropeptide that is implicated in the induction of the synaptic plasticity at the excitatory glutamatergic synapse. It has been shown that PACAP38 induces a form of long-term depression in the hippocampal neurons and transgenic animals, thus indicating its role in learning and memory [13-16]. Moreover, PACAP38 leads to a strong increase of ADAM10 activity through three signaling cascades (PKC, MAP kinase and PI 3-kinase) [17]. Impairing ADAM10 localization and activity at the synapse decreases its processing of N-cadherin. Thus, it induces a modification of the synaptic AMPA receptors, and a significant increase in the size of dendritic spines, both in vitro and in vivo [7].

More recently, Warren et al. [18] have shown the differences in the expression and distribution of ADAM10, MT5-MMP and N-cadherin after traumatic brain injury (TBI), leading to maladaptive synaptic plasticity. MT5MMP and ADAM10 are critical to the success of injuryinduced synaptic plasticity. They displayed time-dependent increases during synaptogenesis, and elevated enzyme activity was concatenated with a reduction of the synaptic adhesion protein, $\mathrm{N}$-cadherin.

ADAM10 inhibition contributes to elevated $\mathrm{N}$-cadherin expression and improves synaptic stability under maladaptive conditions. Sustained N-cadherin expression is reported to underlie both structural and physiological plasticity at the synapse $[6,19,20]$. Furthermore, it was also shown that manipulation of cadherins by either using specific blocking peptide or antibodies, or genetic mutations lead to disruption of $\mathrm{N}$-cadherin molecule that has a 
Table 1 Metzincins implicated in synaptic plasticity and their substrates in the brain

\begin{tabular}{|c|c|c|c|c|}
\hline Family & $\begin{array}{l}\text { Synaptic } \\
\text { substrates }\end{array}$ & Metzincin cleavage & Possible synaptic effects of processing & Refs. \\
\hline Cadherins & N-cadherin & MT5-MMP, ADAM-10 & $\begin{array}{l}\text { Proliferation of neuronal stem cells, neuronal } \\
\text { differentiation, axonal remodeling and } \\
\text { synaptogenesis, modulation of dendritic spine } \\
\text { morphology }\end{array}$ & {$[7-10]$} \\
\hline \multirow[t]{3}{*}{ Syndecans } & Syndecan-1 & $\begin{array}{l}\text { MMP-2, -7, -9, MT1-MMP, } \\
\text { MT3-MMP, ADAM-17 }\end{array}$ & \multirow{3}{*}{$\begin{array}{l}\text { Dendritic spine development, cell adhesion, } \\
\text { neurite guidance, cell migration during } \\
\text { development of CNS }\end{array}$} & \multirow[t]{3}{*}[25,26,28-33]{} \\
\hline & Syndecan-2 & MMP-2, -9 & & \\
\hline & Syndecan-4 & $\begin{array}{l}\text { MMP-2, -9, ADAM-17, } \\
\text { ADAMTS-1, -4 }\end{array}$ & & \\
\hline \multirow[t]{6}{*}{$\begin{array}{l}\text { Immunoglobulin } \\
\text { superfamily }\end{array}$} & NCAM & MMP-2, ADAMs & $\begin{array}{l}\text { Neurite branching and outgrowth, influence on } \\
\text { LTP, structural remodeling of neuronal } \\
\text { connections }\end{array}$ & {$[37,38,46,47]$} \\
\hline & L1-CAM & ADAM-10, -17 & $\begin{array}{l}\text { Neurite outgrowth, neuronal differentiation and } \\
\text { migration }\end{array}$ & {$[41]$} \\
\hline & Nectin-1 & ADAM-10 & $\begin{array}{l}\text { Regulation of the spine density and morphology, } \\
\text { cell-cell interaction, influence on LTP and } \\
\text { LTD }\end{array}$ & [49-51] \\
\hline & SynCAM 1 & ADAM-17 & Modulation of synaptic interactions & {$[51]$} \\
\hline & SynCAM 2 & MMP-9 & Remodeling of dendritic spine structure & {$[56]$} \\
\hline & ICAM-5 & MMP-2, -9 & $\begin{array}{l}\text { Maturation of dendritic spines, cytoskeleton } \\
\text { reorganization, morphological remodeling of } \\
\text { dendritic spines, }\end{array}$ & {$[57,62,63]$} \\
\hline Dystroglycans & $\beta$-dystroglycan & MMP-9 & $\begin{array}{l}\text { Cytoskeleton reorganization, modulation of } \\
\text { dendritic spine morphology }\end{array}$ & {$[65,66]$} \\
\hline Neurexins & $\beta$-neurexin & MMPs & $\begin{array}{l}\text { Regulation of the synapse formation and } \\
\text { stabilization of the connectivity in the CNS }\end{array}$ & {$[69,70]$} \\
\hline \multirow[t]{3}{*}{ Thrombospon-dins } & TSP1 & MMP-2, ADAMTS1 & \multirow[t]{3}{*}{ ND } & \multirow[t]{3}{*}{ [74-79] } \\
\hline & TSP2 & $\begin{array}{l}\text { MMP-2, }-9,-14 \\
\text { ADAMTS1 }\end{array}$ & & \\
\hline & TSP5 & MMPs & & \\
\hline
\end{tabular}

$N D$ not defined

profound and long-lasting effect on synaptic plasticity and memory formation [19, 20]. Moreover, a dysfunction of the cadherin-based adhesive system may alter functional connectivity and information processing in the human brain in neuropsychiatric disorders [21].

Notably, the ectodomain shedding of other members of cadherin family in multiple pathophysiological conditions, including inflammation and cancer, has been observed. For instance, it was demonstrated that vascular endothelial cadherin (VE-cadherin), an endothelial-specific member of cadherin family, that forms a complex with beta-catenin and stabilizes cell-cell adhesion is also cleaved by MMP-7 on the cell membrane of the human umbilical vein endothelial cell. This phenomenon might play an important role in angiogenesis [22]. Moreover, ADAM10-mediated endothelial cadherin (E-cadherin) proteolysis was proposed as a regulatory mechanism in inflammatory epidermal diseases, which are characterized by loss of E-cadherin expression and loss in epithelial integrity [23]. In breast cancer, it was observed that upregulation of the ADAM15 leads to enhance cleavage of E-cadherin [24]. In the brain, during early stage of neural development the presence of E-cadherin has been observed. It was shown that E-cadherin is first expressed in the embryonic ectoderm and plays a role in maintaining of ectoderm and future epidermis architecture together with other cadherins. Soon after neural induction, E-cadherin is replaced by $\mathrm{N}$-cadherin. So far, however, it has apparently not been shown that E-cadherin is processed by metzincins in the brain.

\section{Syndecans}

Syndecans are a major class of heparin sulfate proteoglycans (HSPGs) and are involved in adhesion-induced synaptic modifications. Four members of the syndecan family, syndecan-1, $-2,-3$, and -4 , have been characterized in the mammalian tissues, including the brain. For instance, 
syndecan-2 plays a prominent role in the organization of postsynaptic structures. It is highly concentrated on the spines of mature hippocampal neurons, and plays a critical role in the dendritic spine development [25]. The other member, syndecan-3, is involved in cell adhesion, neurite guidance, and cell migration during development of the nervous system [26]. Moreover, it has been suggested to function as an important modulator of the synaptic plasticity that influences hippocampus-dependent memory [27]. Through interaction with several cytoplasmic proteins, syndecans may provide a molecular link between intracellular cytoskeleton/signaling complex and the extracellular environment at specific sites on the cell surface [25].

It has been shown that syndecans undergo regulated proteolytic shedding from the cell surface. Interestingly, syndecans are differentially cleaved by three classes of metzincins: MMPs, a disintegrin and metalloproteases (ADAMs) and a disintegrin and metalloproteinase with thrombospondin motifs (ADAMTS) proteases. MMP-2 and MMP-9 can cleave syndecans-1, -2 and -4 [28, 29]. MMP-7 and membrane-associated metalloproteinases MT1-MMP and MT3-MMP are known to cleave syndecan-1 [30, 31]. It has recently been demonstrated that ADAM17 is able to shed syndecan-1 and syndecan-4 [32], and the latter is also processed by ADAMTS1 and ADAMTS4 proteases [33]. Moreover, for it has been shown that the remaining portion of the syndecan- 3 can be further processed by the PS $1 / \gamma$ secretase complex. The multiplicity of proteases able to cleave syndecans may result from the heterogeneity of their ectodomains and may depend on the cell type and stimulatory conditions. Hence, still is not clear how extracellular stimuli influence sheddases to mediate syndecan cleavage. Although, the syndecans cleavage was not demonstrated in the brain, it cannot be excluded that some of their neuronal functions may be regulated by proteolysis.

\section{NCAM and L1-CAM}

NCAM and L1 are members of immunoglobulin-like superfamily that were repeatedly implicated in synaptic functions, as well as neuronal migration, neuronal survival, neurite outgrowth, myelination, axon guidance, fasciculation, and regeneration [34-36].

Both NCAM and L1 were shown to be processed by metzincins. Inhibition of NCAM-mediated adhesion with either function-blocking antibodies or synthetic peptides did not affect normal basal synaptic transmission, but reduced E-LTP in area CA1, along with impaired hippocampal-dependent learning [37]. Hinkle et al. [38] revealed that regulated ADAM metalloprotease-induced ectodomain shedding of NCAM down-regulates neurite branching and neurite outgrowth in primary cortical neurons.

In vitro and in vivo studies showed that cleavage of L1 protein is elicited by two sheddases ADAM10 and ADAM17. Both proteases critically affect the physiological functions of L1 adhesion protein. Proteases-mediated disruption of L1-dependent contacts might be an important mechanism for the regulation of the adhesion of migrating neurons. Moreover, ADAM10-dependent releasing of soluble L1 ectodomain from cultured neurons promotes neurite outgrowth and influences neuronal differentiation. In addition, it was shown that NMDA-stimulated $\mathrm{Ca}^{2+}$ influx might be the cause for enhanced ADAM10 activity, leading to increased L1 shedding. This $\mathrm{Ca}^{2+}$ influx is known to affect activity-dependent synaptic plasticity [39]. Besides, L1 is also cleaved by PS1/ $\gamma$-secretase complex. This regulated intramembrane proteolysis process [40], also demonstrated for the $\mathrm{N}$-cadherin or nectin-1, affects signal transduction at the synapse. Furthermore, MatsumotoMiyai et al. [41] found that the plasticity-related L1 is a specific substrate of neuropsin and that this neuropsin-L1 processing system is regulated by neural activity and is involved in the hippocampal plasticity.

NCAMs are involved in the initial phase of long-term potentiation in the hippocampus and learning [42, 43]. It has been reported that NCAM may be cleaved extracellularly in vivo in response to the activation of NMDA receptors during the induction of LTP and in response to seizures [44, 45]. Additionally, Hubschmann et al. [46] have shown that NCAM can be released from the primary hippocampal neurons in vitro and this cleavage involves extracellular ATP and can be inhibited by the metalloproteinase inhibitor. The ATP released either during learning or induction of LTP may target NCAM for proteolysis, and this proteolysis is necessary for the structural remodeling of neuronal connections taking place during consolidation of LTP. All these findings suggest that metalloproteinase activity regulates NCAM-mediated neurite outgrowth, possibly by cleaving NCAM from the extending neurite, thereby reducing adhesion to an immobile environment and thus facilitating further neurite extension [46]. The members of NCAM family are also implicated in aberrant plasticity. It was shown that neural cell adhesion molecules and metzincins, together play an important role in the pathogenesis of experimental autoimmune encephalomyelitis (EAE). The observed elevated level of MMP-2 and impaired expression of NCAM in the hippocampus appear to be critical for both the brain plasticity and underlie a complex autoimmune process in the brain in acute EAE [47].

The expression of the paralog of NCAM, NCAM2 has been proposed to influence certain types of neurological diseases and cancers. Both proteins are abundant in the central nervous system (CNS), suggesting that they also 
may share functional similarities. To date, there is no information about proteolytic cleavage of NCAM2. Nevertheless, it cannot be excluded that in the olfactory system, where NCAM2 is important for the formation or maintenance of the dendritic and axonal compartmentalization, its function might be regulated by proteolysis, similarly to NCAM1 [48].

\section{Nectins}

Nectins are $\mathrm{Ca}^{2+}$-independent immunoglobulin-like adhesion molecules, involved in cell-cell adherent junctions. Nectin-1 ectodomain shedding and intramembrane cleavage occurs in postsynaptic as well as presynaptic membranes, where it is localized [49, 50]. Kim et al. [51] have shown that nectin-1 cleavage plays a role in the regulation of the spine density. It is well documented that activation of NMDA receptors or chemical long-term potentiation (cLTP) result in ADAM10 activation which is one of the major proteases responsible for ectodomain shedding of nectin- 1 in neurons $[49,51]$. The extracellular proteolysis of nectin-1 generates at least two soluble ectodomains [50]. These protein fragments may act as signaling molecules in the synaptic cleft by interacting with other ECM components and thus regulating cell-cell interaction or may bind to their receptors, initiating a cascade of signaling inside the cell. Thus, taken together, these events may influence on changes in density and spine morphology observed during induction of LTP and LTD. On the other hand, the intramembrane domain of nectin-1 released by activity of presenilin-dependent gamma-secretase complex may also serve many roles. The $C$-terminal fragment of nectin- 1 may be translocated into the nucleus and acts as either transcriptional stimulator or repressor. Sequence analysis revealed that this intracellular fragment contains a putative nuclear localization signal (RRRH) right after the transmembrane domain [52]. Moreover, cleavage of nectin-1 releases cytoplasmic proteins such as afadin from peripheral membranes and causes its translocation into the nucleus and thus, may regulate the subcellular localization of afadin between the plasma membrane and the nucleus [53].

\section{SynCAMs}

Synaptic cell adhesion molecules (SynCAMs) belong to the immunoglobulin-like protein family and act as an adhesion molecules in the synaptic cleft forming a homo- and heterophilic transsynaptic adhesion complexes that contributes to synapse organization and function [54]. Tanabe et al. [55] have shown that SynCAM1 can be processed by ADAM17-like proteases at the synapse. The biological importance of this phenomenon may be associated with the modulation of synaptic interaction and plasticity. Recently, using proteomic approach, the cleavage of SynCAM2 via MMP-9 has been demonstrated [56]. SynCAM2 cleavage evoked by MMP-9 might influence the remodeling of the dendritic spine structure in response to synaptic transmission. It indicates that different SynCAMs can be cleaved by various types of proteases, however, the exact mechanism of this process still remains unknown.

\section{ICAM-5}

Tian et al. [57], showed that intercellular adhesion molecule-5 (ICAM-5), protein specifically expressed in postnatal excitatory neuronal cell bodies, dendritic shafts, and dendritic filopodia of the telencephalon [58, 59], is a substrate for either MMP-2 or MMP-9. Upon neuronal stimulation, ICAM-5 cleavage driven by MMPs, caused the dendritic spines maturation and elongation of filopodia. Moreover, blocking of MMP-2 and MMP-9 by specific inhibitor as well as ICAM-5 deficiency led to the retraction of the spine heads and a decreased number of spines in response to NMDA stimulation [57]. The mechanism of spine remodeling through MMPs dependent ICAM-5 cleavage has been proposed $[60,61]$. In neurons, stimulation of either NMDA or AMPA receptors for glutamate leads to enhancement of MMP-2 and MMP-9 activity, resulting in processing of ICAM-5 from immature nascent spines. The shedding of ICAM-5 may facilitate local membrane and cytoskeleton reorganization, and thereby morphological remodeling of the dendritic spines [57]. In addition, recent results have shown that ICAM-5 can be also cleaved by exogenous MMP-3 and MMP-7, in response to neuronal activation by either NMDA treatment or induction of LTP [62].

Furthermore, it was shown that soluble ICAM-5 is generated with cLTP. The $N$-terminal domain of ICAM-5 is able to stimulate integrin dependent actin polymerization within dendrites, and thus spine expansion. In addition, the inhibition of MMPs activity and blocking of $\beta 1$ integrins diminished ICAM-5 dependent effects. Overall, these findings indicate that MMPs and soluble ICAM-5 have the potential to influence neuronal excitability [63].

\section{$\beta$-Dystroglycan}

Dystroglycan is a part of dystrophin-glycoprotein complex that links dystrophin and the intracellular cytoskeleton with extracellular matrix and anchors the whole complex at the membrane [64]. DG is composed of $\alpha$ - and $\beta$-subunits. $\alpha$-dystroglycan ( $\alpha$-DG) is a highly glycosylated extracellular 
component, whereas $\beta$-DG spans the plasma membrane forming a bridge between $\alpha$-DG and the cytoskeleton [65]. Michaluk et al. [66] have shown that MMP-9 driven $\beta$-DG proteolysis occurs in response to synaptic activity in neuronal cultures and in the hippocampus in response to seizures. Simultaneously, in neurons, after treatment with specific inhibitor (TIMP-1) blocking MMP-9 activity and in MMP-9 knockout mice, the appearance of truncated form of the protein was not observed. So far, the exact consequences of $\beta$-dystroglycan cleavage are not known, however, a growing body of evidence suggests a functional role for the entire dystrophin-glycoprotein complex at central synapses and in their plasticity. For instance, it was shown that mice selectively deficient in the brain dystroglycan suffer from late phase of long term potentiation deficits in the hippocampus [65]. Moreover, mutations in the genes encoding dystroglycan-binding proteins such as laminin, its extracellular ligand, as well as dystrophin, are associated with mental retardation. Notably, specific changes in the hippocampal expression patterns of transcripts encoding dystrophin and neurexins, presynaptic interacting partners of DG, following kainate and PTZ treatment in vivo have been previously demonstrated $[67,68]$.

\section{$\beta$-Neurexin}

It was also established that cell surface adhesion receptors undergo proteolytic cleavage in the synaptic cleft. Among them, it was shown that biological role of $\beta$-neurexin is closely associated with its proteolytic processing. The presynaptic receptors neurexins (NRXs), and their ligands, postsynaptic neuroligins (NLs) are two families of synapse-specific adhesion molecules critically involved in regulation of the synapse formation and stabilization of the connectivity in the central nervous system. It was demonstrated that mutations in neurexins may lead to synaptic defects associated with brain disorders (e.g. mental retardation, autism). Studies by several independent groups have shown that neurexins can be proteolytically processed at the synapse [69, 70]. Thus, both in vitro and in vivo neurexins are sequentially cleaved by metalloprotease- and PS $1 / \gamma$-secretase dependent activities. In neurons, accumulated $N$ - and $C$-terminal fragments of $\beta$-neurexin play a dual role, as signaling molecule in the extracellular milieu as well as in the intracellular space.

\section{Thrombospondins}

Thrombospondins (TSPs) are involved in cell-cell interactions and synaptogenesis and have the ability to bind to the matrix proteins, proteinases, growth factors, and cell surface receptors. Recently, it was shown that thrombospondin 1 and thrombospondin 2 promote synaptogenesis, both in vitro and in vivo, and their deficiency results in reduced synaptic density during development [71]. Moreover, both of them are involved in modulation of the synaptic plasticity and axonal sprouting after ischemic injury [72]. However, one of the best described roles of TSP1 is action as an anti-angiogenic agent. TSPs functions have been well established in cancer biology where angiogenesis is essential for tumor growth [73].

To date, many reports indicate that TSPs are processed by various proteases in extracellular matrix. It was shown that ADAMTSs are involved in the processing of extracellular glycoproteins, including TSP1 and TSP2 [74]. For instance, cleavage of TSP 1 and TSP 2 by ADAMTS 1 could modulate their functions by facilitate remodeling of matrixassociated TSP [75]. Furthermore, most recently, the global proteomic studies discovered that TSPs are also targets for other metzincins. Hence, thrombospondin-1 and thrombospondin-2 are MMP-2 [76] and MMP-14 [77] substrates, respectively. Moreover, for thrombospondin-2 the cleavage by MMP-2 and MMP-9 was confirmed [78]. TSP5 was also shown to be proteolytically processed by different MMPs in vitro [79]. Nevertheless, despite the established role of TSPs in the brain, especially during synaptogenesis, so far, there is no direct data about the regulation of these proteins by proteolysis.

\section{Future Directions}

Interest in the identification of proteodegradome in the extracellular matrix, including discovering of the new targets for proteases and understanding their function, has intensified in recent years in a hope to increase our knowledge of the synaptic machinery. In this review, we emphasize that cell adhesion molecules play not only scaffolding role in the synaptic cleft, but foremost are capable to modulate the functional and structural aspects of the synaptic plasticity in both normal and pathological conditions. It has to be noted that presented list of CAMs which undergo proteolytic turnover at the synapse is still open. Completion of genome sequences for many organisms allows to protein classification into the respective clusters. Based on individual protein domain structures for extracellular matrix proteins the ECM and adhesion proteins, the concepts of "matrisome" and "adhesome" have been implemented $[75,76]$. This opens a window for classification of new ECM and ECM-associated proteins as important in regulation of the synaptic plasticity and understanding how these components can influence neuronal network dynamics. 
Acknowledgments This work was supported by ERA-NET NEURON MODDIFSYN grant to LK.

Conflict of interest The authors declare that they have no conflict of interest.

Open Access This article is distributed under the terms of the Creative Commons Attribution License which permits any use, distribution, and reproduction in any medium, provided the original author(s) and the source are credited.

\section{References}

1. Benson DL, Huntley GW (2012) Building and remodeling synapses. Hippocampus 22(5):954-968

2. Rivera S, Khrestchatisky M, Kaczmarek L, Rosenberg GA, Jaworski DM (2010) Metzincin proteases and their inhibitors: foes or friends in nervous system physiology? J Neurosci 30(46): $15337-15357$

3. Dityatev A (2010) Remodeling of extracellular matrix and epileptogenesis. Epilepsia 51(Suppl 3):61-65

4. Dzwonek J, Rylski M, Kaczmarek L (2004) Matrix metalloproteinases and their endogenous inhibitors in neuronal physiology of the adult brain. FEBS Lett 567(1):129-135

5. Page-McCaw A, Ewald AJ, Werb Z (2007) Matrix metalloproteinases and the regulation of tissue remodelling. Nat Rev 8(3): 221-233

6. Bozdagi O, Shan W, Tanaka H, Benson DL, Huntley GW (2000) Increasing numbers of synaptic puncta during late-phase LTP: $\mathrm{N}$-cadherin is synthesized, recruited to synaptic sites, and required for potentiation. Neuron 28(1):245-259

7. Malinverno M, Carta M, Epis R, Marcello E, Verpelli C, Cattabeni F, Sala C, Mulle C, Di Luca M, Gardoni F (2010) Synaptic localization and activity of ADAM10 regulate excitatory synapses through $\mathrm{N}$-cadherin cleavage. J Neurosci 30(48): 16343-16355

8. Reiss K, Maretzky T, Ludwig A, Tousseyn T, de Strooper B, Hartmann D, Saftig P (2005) ADAM10 cleavage of N-cadherin and regulation of cell-cell adhesion and beta-catenin nuclear signalling. EMBO J 24(4):742-752

9. Uemura K, Kihara T, Kuzuya A, Okawa K, Nishimoto T, Ninomiya H, Sugimoto H, Kinoshita A, Shimohama S (2006) Characterization of sequential N-cadherin cleavage by ADAM10 and PS1. Neurosci Lett 402(3):278-283

10. Folgueras AR, Valdes-Sanchez T, Llano E, Menendez L, Baamonde A, Denlinger BL, Belmonte C, Juarez L, Lastra A, Garcia-Suarez O, Astudillo A, Kirstein M, Pendas AM, Farinas I, Lopez-Otin C (2009) Metalloproteinase MT5-MMP is an essential modulator of neuro-immune interactions in thermal pain stimulation. Proc Natl Acad Sci USA 106(38):16451-16456

11. Ebinu JO, Yankner BA (2002) A RIP tide in neuronal signal transduction. Neuron 34(4):499-502

12. Gardoni F, Saraceno C, Malinverno M, Marcello E, Verpelli C, Sala C, Di Luca M (2011) The neuropeptide PACAP38 induces dendritic spine remodeling through ADAM10-N-cadherin signaling pathway. J Cell Sci 125(6):1401-1406

13. Kondo T, Tominaga T, Ichikawa M, Iijima T (1997) Differential alteration of hippocampal synaptic strength induced by pituitary adenylate cyclase activating polypeptide-38 (PACAP-38). Neurosci Lett 221(2-3):189-192

14. Roberto M, Scuri R, Brunelli M (2001) Differential effects of PACAP-38 on synaptic responses in rat hippocampal CA1 region. Learning \& memory (Cold Spring Harbor, NY) 8 (5): 265-271
15. Ster J, de Bock F, Bertaso F, Abitbol K, Daniel H, Bockaert J, Fagni L (2009) Epac mediates PACAP-dependent long-term depression in the hippocampus. J Physiol 587(1):101-113

16. Yang K, Lei G, Jackson MF, Macdonald JF (2010) The involvement of PACAP/VIP system in the synaptic transmission in the hippocampus. J Mol Neurosci 42(3):319-326

17. Kojro E, Postina R, Buro C, Meiringer C, Gehrig-Burger K, Fahrenholz F (2006) The neuropeptide PACAP promotes the alpha-secretase pathway for processing the Alzheimer amyloid precursor protein. Faseb J 20(3):512-514

18. Warren KM, Reeves TM, Phillips LL (2012) MT5-MMP, ADAM-10, and N-Cadherin Act in concert to facilitate synapse reorganization after traumatic brain injury. J Neurotrauma 29(10): 1922-1940

19. Mysore SP, Tai CY, Schuman EM (2007) Effects of N-cadherin disruption on spine morphological dynamics. Frontiers Cell Neurosci 1(1). doi:10.3389/neuro.03.001.2007

20. Tang L, Hung CP, Schuman EM (1998) A role for the cadherin family of cell adhesion molecules in hippocampal long-term potentiation. Neuron 20(6):1165-1175

21. Redies C, Hertel N, Hubner CA (2012) Cadherins and neuropsychiatric disorders. Brain Res 1470:130-144

22. Ichikawa Y, Ishikawa T, Momiyama N, Kamiyama M, Sakurada H, Matsuyama R, Hasegawa S, Chishima T, Hamaguchi Y, Fujii S, Saito S, Kubota K, Hasegawa S, Ike H, Oki S, Shimada H (2006) Matrilysin (MMP-7) degrades VE-cadherin and accelerates accumulation of beta-catenin in the nucleus of human umbilical vein endothelial cells. Oncol Rep 15(2):311-315

23. Maretzky T, Scholz F, Koten B, Proksch E, Saftig P, Reiss K (2008) ADAM10-mediated E-cadherin release is regulated by proinflammatory cytokines and modulates keratinocyte cohesion in eczematous dermatitis. J Invest Dermatol 128(7):1737-1746

24. Najy AJ, Day KC, Day ML (2008) The ectodomain shedding of E-cadherin by ADAM15 supports ErbB receptor activation. J Biol Chem 283(26):18393-18401

25. Ethell IM, Yamaguchi Y (1999) Cell surface heparan sulfate proteoglycan syndecan-2 induces the maturation of dendritic spines in rat hippocampal neurons. J Cell Biol 144(3):575-586

26. Raulo E, Chernousov MA, Carey DJ, Nolo R, Rauvala H (1994) Isolation of a neuronal cell surface receptor of heparin binding growth-associated molecule (HB-GAM). Identification as N-syndecan (syndecan-3). J Biol Chem 269(17):12999-13004

27. Kaksonen M, Pavlov I, Voikar V, Lauri SE, Hienola A, Riekki R, Lakso M, Taira T, Rauvala H (2002) Syndecan-3-deficient mice exhibit enhanced LTP and impaired hippocampus-dependent memory. Mol Cell Neurosci 21(1):158-172

28. Brule S, Charnaux N, Sutton A, Ledoux D, Chaigneau T, Saffar L, Gattegno L (2006) The shedding of syndecan- 4 and syndecan-1 from HeLa cells and human primary macrophages is accelerated by SDF-1/CXCL12 and mediated by the matrix metalloproteinase-9. Glycobiology 16(6):488-501

29. Fears CY, Gladson CL, Woods A (2006) Syndecan-2 is expressed in the microvasculature of gliomas and regulates angiogenic processes in microvascular endothelial cells. J Biol Chem 281(21):14533-14536

30. Li Q, Park PW, Wilson CL, Parks WC (2002) Matrilysin shedding of syndecan-1 regulates chemokine mobilization and transepithelial efflux of neutrophils in acute lung injury. Cell 111(5): 635-646

31. Endo K, Takino T, Miyamori H, Kinsen H, Yoshizaki $T$, Furukawa M, Sato H (2003) Cleavage of syndecan-1 by membrane type matrix metalloproteinase-1 stimulates cell migration. J Biol Chem 278(42):40764-40770

32. Pruessmeyer J, Martin C, Hess FM, Schwarz N, Schmidt S, Kogel T, Hoettecke N, Schmidt B, Sechi A, Uhlig S, Ludwig A (2010) A disintegrin and metalloproteinase 17 (ADAM17) mediates 
inflammation-induced shedding of syndecan-1 and -4 by lung epithelial cells. J Biol Chem 285(1):555-564

33. Rodriguez-Manzaneque JC, Carpizo D, Plaza-Calonge Mdel C, Torres-Collado AX, Thai SN, Simons M, Horowitz A, IruelaArispe ML (2009) Cleavage of syndecan-4 by ADAMTS1 provokes defects in adhesion. Int J Biochem Cell Biol 41(4):800-810

34. Maretzky T, Schulte M, Ludwig A, Rose-John S, Blobel C, Hartmann D, Altevogt P, Saftig P, Reiss K (2005) L1 is sequentially processed by two differently activated metalloproteases and presenilin/gamma-secretase and regulates neural cell adhesion, cell migration, and neurite outgrowth. Mol Cell Biol 25(20):9040-9053

35. Povlsen GK, Ditlevsen DK, Berezin V, Bock E (2003) Intracellular signaling by the neural cell adhesion molecule. Neurochem Res 28(1):127-141

36. Kiss JZ, Muller D (2001) Contribution of the neural cell adhesion molecule to neuronal and synaptic plasticity. Rev Neurosci 12(4):297-310

37. Sytnyk V, Leshchyns'ka I, Nikonenko AG, Schachner M (2006) NCAM promotes assembly and activity-dependent remodeling of the postsynaptic signaling complex. J Cell Biol 174(7):1071-1085

38. Hinkle CL, Diestel S, Lieberman J, Maness PF (2006) Metalloprotease-induced ectodomain shedding of neural cell adhesion molecule (NCAM). J Neurobiol 66(12):1378-1395

39. Castellani GC, Quinlan EM, Cooper LN, Shouval HZ (2001) A biophysical model of bidirectional synaptic plasticity: dependence on AMPA and NMDA receptors. Proc Natl Acad Sci USA 98(22):12772-12777

40. Brown MS, Ye J, Rawson RB, Goldstein JL (2000) Regulated intramembrane proteolysis: a control mechanism conserved from bacteria to humans. Cell 100(4):391-398

41. Matsumoto-Miyai K, Ninomiya A, Yamasaki H, Tamura H, Nakamura Y, Shiosaka S (2003) NMDA-dependent proteolysis of presynaptic adhesion molecule L1 in the hippocampus by neuropsin. J Neurosci 23(21):7727-7736

42. Cambon K, Hansen SM, Venero C, Herrero AI, Skibo G, Berezin V, Bock E, Sandi C (2004) A synthetic neural cell adhesion molecule mimetic peptide promotes synaptogenesis, enhances presynaptic function, and facilitates memory consolidation. J Neurosci 24(17):4197-4204

43. Polo-Parada L, Bose CM, Plattner F, Landmesser LT (2004) Distinct roles of different neural cell adhesion molecule (NCAM) isoforms in synaptic maturation revealed by analysis of NCAM $180 \mathrm{kDa}$ isoform-deficient mice. J Neurosci 24(8):1852-1864

44. Fazeli MS, Breen K, Errington ML, Bliss TV (1994) Increase in extracellular NCAM and amyloid precursor protein following induction of long-term potentiation in the dentate gyrus of anaesthetized rats. Neurosci Lett 169(1-2):77-80

45. Hoffman KB, Larson J, Bahr BA, Lynch G (1998) Activation of NMDA receptors stimulates extracellular proteolysis of cell adhesion molecules in hippocampus. Brain Res 811(1-2):152-155

46. Hubschmann MV, Skladchikova G, Bock E, Berezin V (2005) Neural cell adhesion molecule function is regulated by metalloproteinase-mediated ectodomain release. J Neurosci Res 80(6): 826-837

47. Jovanova-Nesic K, Shoenfeld Y (2006) MMP-2, VCAM-1 and NCAM-1 expression in the brain of rats with experimental autoimmune encephalomyelitis as a trigger mechanism for synaptic plasticity and pathology. J Neuroimmunol 181(1-2):112-121

48. Winther M, Berezin V, Walmod PS (2012) NCAM2/OCAM/ RNCAM: cell adhesion molecule with a role in neuronal compartmentalization. Int J Biochem Cell Biol 44(3):441-446

49. Kim J, Chang A, Dudak A, Federoff HJ, Lim ST (2011) Characterization of nectin processing mediated by presenilin-dependent gamma-secretase. J Neurochem 119(5):945-956
50. Lim ST, Chang A, Giuliano RE, Federoff HJ (2012) Ectodomain shedding of nectin- 1 regulates the maintenance of dendritic spine density. J Neurochem 120(5):741-751

51. Kim J, Lilliehook C, Dudak A, Prox J, Saftig P, Federoff HJ, Lim ST (2010) Activity-dependent alpha-cleavage of nectin-1 is mediated by a disintegrin and metalloprotease 10 (ADAM10). J Biol Chem 285(30):22919-22926

52. Marambaud P, Wen PH, Dutt A, Shioi J, Takashima A, Siman R, Robakis NK (2003) A CBP binding transcriptional repressor produced by the PS1/epsilon-cleavage of $\mathrm{N}$-cadherin is inhibited by PS1 FAD mutations. Cell 114(5):635-645

53. Buchert M, Poon C, King JA, Baechi T, D’Abaco G, Hollande F, Hovens CM (2007) AF6/s-afadin is a dual residency protein and localizes to a novel subnuclear compartment. J Cell Physiol 210(1):212-223

54. Fogel AI, Akins MR, Krupp AJ, Stagi M, Stein V, Biederer T (2007) SynCAMs organize synapses through heterophilic adhesion. J Neurosci 27(46):12516-12530

55. Tanabe Y, Kasahara T, Momoi T, Fujita E (2008) Neuronal RA175/SynCAM1 isoforms are processed by tumor necrosis factor-alpha-converting enzyme (TACE)/ADAM17-like proteases. Neurosci Lett 444(1):16-21

56. Bajor M, Michaluk P, Gulyassy P, Kekesi AK, Juhasz G, Kaczmarek L (2012) Synaptic cell adhesion molecule-2 and collapsin response mediator protein-2 are novel members of the matrix metalloproteinase-9 degradome. J Neurochem 122(4): 775-788

57. Tian L, Stefanidakis M, Ning L, Van Lint $P$, Nyman-Huttunen $H$, Libert C, Itohara S, Mishina M, Rauvala H, Gahmberg CG (2007) Activation of NMDA receptors promotes dendritic spine development through MMP-mediated ICAM-5 cleavage. J Cell Biol 178(4):687-700

58. Benson DL, Yoshihara Y, Mori K (1998) Polarized distribution and cell type-specific localization of telencephalin, an intercellular adhesion molecule. J Neurosci Res 52(1):43-53

59. Mitsui S, Saito M, Hayashi K, Mori K, Yoshihara Y (2005) A novel phenylalanine-based targeting signal directs telencephalin to neuronal dendrites. J Neurosci 25(5):1122-1131

60. Tian L, Nyman H, Kilgannon P, Yoshihara Y, Mori K, Andersson LC, Kaukinen S, Rauvala H, Gallatin WM, Gahmberg CG (2000) Intercellular adhesion molecule- 5 induces dendritic outgrowth by homophilic adhesion. J Cell Biol 150(1):243-252

61. Matsuno H, Okabe S, Mishina M, Yanagida T, Mori K, Yoshihara Y (2006) Telencephalin slows spine maturation. J Neurosci 26(6):1776-1786

62. Conant K, Wang Y, Szklarczyk A, Dudak A, Mattson MP, Lim ST (2010) Matrix metalloproteinase-dependent shedding of intercellular adhesion molecule- 5 occurs with long-term potentiation. Neuroscience 166(2):508-521

63. Niedringhaus M, Chen X, Dzakpasu R, Conant K (2012) MMPs and Soluble ICAM-5 increase neuronal excitability within in vitro networks of hippocampal neurons. PLoS ONE 7(8):e42631

64. Ibraghimov-Beskrovnaya O, Ervasti JM, Leveille CJ, Slaughter CA, Sernett SW, Campbell KP (1992) Primary structure of dystrophin-associated glycoproteins linking dystrophin to the extracellular matrix. Nature 355(6362):696-702

65. Moore SA, Saito F, Chen J, Michele DE, Henry MD, Messing A, Cohn RD, Ross-Barta SE, Westra S, Williamson RA, Hoshi T, Campbell KP (2002) Deletion of brain dystroglycan recapitulates aspects of congenital muscular dystrophy. Nature 418(6896): $422-425$

66. Michaluk P, Kolodziej L, Mioduszewska B, Wilczynski GM, Dzwonek J, Jaworski J, Gorecki DC, Ottersen OP, Kaczmarek L (2007) Beta-dystroglycan as a target for MMP-9, in response to enhanced neuronal activity. J Biol Chem 282(22):16036-16041 
67. Gorecki DC, Lukasiuk K, Szklarczyk A, Kaczmarek L (1998) Kainate-evoked changes in dystrophin messenger RNA levels in the rat hippocampus. Neuroscience 84(2):467-477

68. Gorecki DC, Szklarczyk A, Lukasiuk K, Kaczmarek L, Simons JP (1999) Differential seizure-induced and developmental changes of neurexin expression. Mol Cell Neurosci 13(3):218-227

69. Saura CA, Servian-Morilla E, Scholl FG (2011) Presenilin/ gamma-secretase regulates neurexin processing at synapses. PLoS ONE 6(4):e19430

70. Bot N, Schweizer C, Ben Halima S, Fraering PC (2011) Processing of the synaptic cell adhesion molecule neurexin-3beta by Alzheimer disease alpha- and gamma-secretases. J Biol Chem 286(4):2762-2773

71. Christopherson KS, Ullian EM, Stokes CC, Mullowney CE, Hell JW, Agah A, Lawler J, Mosher DF, Bornstein P, Barres BA (2005) Thrombospondins are astrocyte-secreted proteins that promote CNS synaptogenesis. Cell 120(3):421-433

72. Liauw J, Hoang S, Choi M, Eroglu C, Choi M, Sun GH, Percy M, Wildman-Tobriner B, Bliss T, Guzman RG, Barres BA, Steinberg GK (2008) Thrombospondins 1 and 2 are necessary for synaptic plasticity and functional recovery after stroke. J Cereb Blood Flow Metab 28(10):1722-1732

73. Zhang X, Kazerounian S, Duquette M, Perruzzi C, Nagy JA, Dvorak HF, Parangi S, Lawler J (2009) Thrombospondin-1 modulates vascular endothelial growth factor activity at the receptor level. Faseb J 23(10):3368-3376
74. Lee NV, Sato M, Annis DS, Loo JA, Wu L, Mosher DF, IruelaArispe ML (2006) ADAMTS1 mediates the release of antiangiogenic polypeptides from TSP1 and 2. EMBO J 25(22): 5270-5283

75. Nicosia RF, Tuszynski GP (1994) Matrix-bound thrombospondin promotes angiogenesis in vitro. J Cell Biol 124(1-2):183-193

76. Dean RA, Overall CM (2007) Proteomics discovery of metalloproteinase substrates in the cellular context by iTRAQ labeling reveals a diverse MMP-2 substrate degradome. Mol Cell Proteomics 6(4):611-623

77. Butler GS, Dean RA, Tam EM, Overall CM (2008) Pharmacoproteomics of a metalloproteinase hydroxamate inhibitor in breast cancer cells: dynamics of membrane type 1 matrix metalloproteinase-mediated membrane protein shedding. Mol Cell Biol 28(15):4896-4914

78. Prudova A, Auf Dem Keller U, Butler GS, Overall CM (2010) Multiplex N-terminome analysis of MMP-2 and MMP-9 substrate degradomes by iTRAQ-TAILS quantitative proteomics. Mol Cell Proteomics 9(5):894-911

79. Dickinson SC, Vankemmelbeke MN, Buttle DJ, Rosenberg K, Heinegard D, Hollander AP (2003) Cleavage of cartilage oligomeric matrix protein (thrombospondin-5) by matrix metalloproteinases and a disintegrin and metalloproteinase with thrombospondin motifs. Matrix Biol 22(3):267-278 